\title{
International Interdependence between Cash Crop and Staple Food Futures Price Indices: A Dynamic Assessment
}

\author{
El Mamoun Amrouk ${ }^{1,2, *}$, Thomas Heckelei ${ }^{1}$ and Stephanie-Carolin Grosche ${ }^{1}$ \\ ${ }^{1}$ Institute for Food and Resource Economics, University of Bonn, Bonn, Germany and ${ }^{2}$ Food and Agriculture Organization of \\ the United Nations (FAO), Rome, Italy \\ ${ }^{*}$ Corresponding author. Email: elmamoun.amrouk@fao.org
}

\begin{abstract}
:
This study examines the price level and volatility interaction between international staple food and cash crop futures price indices. Understanding the relationship between these commodities bears significant implications for low-income food deficit countries that depend on cash crops to finance food import bills. We use a wavelet analysis to decompose the price indices and then apply a BEKK-MGARCH (Baba, Engle, Kraft and Kroner-multivariate generalized autoregressive conditional heteroskedasticity) approach to analyze the relationship across timescales. Results indicate the level of correlation and volatility linkages are strongest at lower frequencies (longer run) than at higher timescales (short run), with information running from staple food to cash crop markets.
\end{abstract}

Keywords: Cash crops; MGARCH; staple food crops; volatility spillover; wavelet

\section{Introduction}

For many low-income food deficit countries (LIFDCs), ${ }^{1}$ swings in staple food prices are an important source of macroeconomic instability. Theory suggests that in the face of instable current accounts, attributable to relatively volatile export earnings and/or import bills, agents should seek to enhance savings, a move that enables smoothing consumption over time (Ghosh and Ostry, 1994). Still, the ability to increase the level of savings is rather limited in many poor net food importing developing countries, mainly because of weak domestic financial systems. Countries can also try to borrow funds from international markets to finance import requirements, thus balancing a current account deficit with higher capital inflows. This is possible provided countries still have the ability to sustain additional borrowing without prompting a rise in default risks.

In this context of limited access to savings and borrowing, cash crop export earnings can act as an automatic consumption smoothing mechanism for LIFDCs. This is because international demand for agricultural commodities (including cash crops) is generally inelastic, implying that movements in prices outweigh those of quantities (Food and Agriculture Organization of the United Nations [FAO], 2004). Hence, rising cash crop and staple food prices translate into increasing export earnings and import bills. A casual review of price data series shows that staple food and cash crop quotations tend to display synchronized behavior. For example, during the

\footnotetext{
${ }^{1} \mathrm{~A}$ list of the LIFDCs is available at http://www.fao.org/countryprofiles/lifdc/en/. Criteria for inclusion are also provided. 
recent commodity price surge episode, wheat and rice prices went up by $17 \%$ and $65 \%$, between 2006 and 2009, respectively, while international prices for coffee, tea, and sugar, grew by $26 \%$, $45 \%$, and 23\%, over the same period, respectively. ${ }^{2}$ Overall, between 2002 and 2008, the World Bank agricultural subindex increased by $102.9 \%$. The rise in cash crop prices, together with staple food prices, means that export revenues from the commodities that many LIFDCs rely on could act as a good hedge against surges in food import bills and contribute to reducing current account instability. ${ }^{3}$

This study looks at one particular aspect of current account instability that relates to the extent to which changes in cash crop prices can dampen the effect of higher food prices. ${ }^{4} \mathrm{We}$ explore the price relationship by examining comovements and dynamics in terms of price level and volatility. Although movements in quantities together with prices determine the direction and magnitude of export earnings, the focus in this article is exclusively on the price component of the equation given its relative importance. Volatility is important to study because it helps shed some light on the transmission of information/uncertainty from one market to another. Research also indicates that the prevalence of high volatility hinders investment and planning.

In order to gain further insights into the staple food-cash crops price relationship, we apply a wavelet analysis to decompose the series into three timescale levels corresponding to the short, medium, and long run. That is because policy implications differ depending on the nature of the price linkages at each time horizon. For instance, if the price dynamics are stronger in the long run, as opposed to the short run, cash crop earnings could potentially limit, or offset, rises in international food prices, whereas in the short run, measures may be required to address current account imbalances. Further, the application of wavelet analysis enables the detection of breaks or any sudden changes in the dynamics that may characterize the series.

After decomposing the series, a multivariate Baba, Engle, Kraft, and Kroner (BEKK)-generalized autoregressive conditional heteroskedasticity (GARCH) framework (Engle and Kroner, 1995) is applied to explore the dynamics of the volatility interaction and conditional correlation at various frequency levels. The advantage of using the BEKK framework is that it ensures a symmetric and positive definite conditional variance-covariance matrix. In addition, the model produces fewer parameter estimates compared with other multivariate GARCH (MGARCH) models when evaluating volatility transmission across markets (Gardebroek and Hernandez, 2013). To minimize the effect of model convergence issues that are often associated with BEKK-GARCH parameterization, we construct two price indices that we use for the estimation exercise. The first price index captures daily futures price changes for sugar, cotton, cocoa, and coffee and is referred to as the cash crop price index. The second index depicts daily futures price changes for wheat, maize, and soybeans and represents the staple food crop price index. Both price indices are volume weighted, with data on daily volumes obtained from the futures markets where the commodity is traded..$^{5}$ The idea of weighting by volume is to give prominence to the commodities in the price index that are traded the most. ${ }^{6}$ Note that the data show a jump in the assigned weights as the contract expiry date nears. Nonetheless, these changes do not alter the relative importance of specific commodities in the index. That is, sugar and maize remain the most traded contracts regardless of the changes in weights

\footnotetext{
${ }^{2}$ See the World Bank's pink sheet at: http://www.worldbank.org/en/research/commodity-markets.

${ }^{3}$ In 2013, for instance, export of tropical beverage crops, fruits, and sugar as a percentage of total agricultural products was estimated at $77 \%, 74 \%$, and $71 \%$ for Burundi, Mauritius, and Swaziland, respectively. Also in that year, these products accounted for $43 \%, 27 \%$, and $24 \%$ of total merchandise export for Burundi, Uganda, and Kenya, respectively (FAO, 2016).

${ }^{4}$ International prices, such as those for coffee, cocoa, and wheat, are generally assumed to refer to futures prices like those negotiated at the Intercontinental Exchange (ICE) and the Chicago Board of Trade (CBOT). Futures prices are relevant because they influence border prices and, hence, the value of import bills and export earnings (Chen, Rogoff, and Rossi, 2010).

${ }^{5}$ Sugar, cotton, cocoa, and coffee daily futures prices and volumes are taken from the ICE, New York, whereas those for wheat, maize, and soybeans are taken from the CBOT, Chicago.

${ }^{6}$ For the food index, maize has an average weight of $52 \%$ over the sample period, while for the cash crop index, sugar represents an average of about $64 \%$ of the index.
} 
because of the effect of expiring contracts. Scaling the estimated conditional covariances by the estimated conditional variances yields a series of conditional correlations, which permit the examination of conditional correlation patterns between the cash crop and staple food indices at different timescales.

In addition to easing model convergence, undertaking the analysis at the aggregate level offers some insights into the relationship between cash crop and staple food international prices, before deciding on whether it is "worth" exploring further the analysis at the country level, given the challenges associated with the data. Indeed, data series on cash crop and staple food prices for developing countries are often short, contain missing values, and are generally available at low frequency only, which makes it difficult to obtain robust results using a BEKK-GARCH approach.

Our research contributes to the literature in four aspects. First, as opposed to the bulk of the existing studies on the relationship between staple foods and cash crops, we examine the price level and volatility interaction from a global perspective. Hence, we contribute to providing evidence-based analysis of the potential contribution of cash crop export earnings to food import bills, particularly during periods when food prices are relatively high and volatile. Second, we use wavelet transforms to decompose the price series into different timescales, enabling an assessment of volatility dynamics otherwise hidden in the original series. Third, we estimate conditional correlations between cash crops and staple food indices at difference time frequency domains. This way, we evaluate the potential dampening effect of cash crop export earnings on current account variability because of rising food import prices. Finally, the literature on the linkages between balance of payments and commodity export/import is quite substantive, with marked contributions from international organizations, including the FAO (2016), the International Monetary Fund (IMF, 2008), and the United Nations Conference on Trade and Development (UNCTAD and FAO, 2017). As if often the case, member countries of these organizations (notably through the Group of 77, an intergovernmental group of developing countries) request that normative work be carried out on this topic, given its practical relevance. This article adds to that research stream.

We should note that the observed synchronized movement between cash and staple food international prices cannot be explained by market fundamentals only, at least in the short term. That is because the substitution possibility in consumption and production between cash crops and staples in the physical market is limited and, hence, cannot explain the extent of price correlation. On the other hand, macroeconomic shocks, weather impacts affecting major producers of both commodity groups, changes in energy prices, and the potential influence of institutional investors could cause futures prices to comove. The influence of institutional investors on commodity markets still remains ambiguous (Fattouh, Kilian, and Mahadeva, 2012; Hamilton and $\mathrm{Wu}, 2015$; Irwin and Sanders, 2011). A causal attribution analysis is beyond the scope of this study. Figure A2 (see Appendix) describes the main linkages between cash crop and staple food markets and some of the possible factors underlying the relationship.

The rest of the article is organized as follows: Section 2 covers a short review of relevant studies on cash crops and staples and the use of the GARCH methodology. We then present a discussion on the methodology and data used in the analysis (Section 3), followed by a discussion about the main empirical results and observations (Section 4). Finally, a summary of the main conclusions and implications is provided in Section 5.

\section{Literature review}

The literature on the relationship between international staple food and cash crop prices is mostly concerned with farm resource allocation and, precisely, whether cash crop production and export compete for resources with food crop production. The concern is that a focus on cash 
crop production may create some risks for smallholder farm households, notably in terms of food security. One school of thought argues that cash crop production is detrimental to food security (Maxwell and Fernando, 1989; Mittal, 2009), whereas others contend that a cash crop strategy improves farm welfare because proceeds from cash crops provide the means to buy food in the local market (i.e., the access dimension of food security) (Timmer, 1997; Von Braun and Kennedy, 1986; Weber et al., 1988). Recent papers in this field claim that staple foods and cash crops should be viewed as complementary rather than competitive. By participating in cash crop schemes, smallholders can have access to productivity enhancing inputs such as credits, management training, fertilizers, and other factor inputs that would not have been available without the participation in cash crop programs (Govereh and Jayne, 2003; Theriault and Tschirley, 2014).

Although many studies provide some interesting insights into the mechanisms that explain the allocation of farm resources to the production of cash crops by smallholders in developing countries (Norton and Hazell, 1986), they seldom address the interaction of cash crop and staple food prices at the international market level. The dynamics at the international level are relevant because they often determine movements in domestic prices. For example, coffee prices received by farmers in Ghana are associated with futures prices negotiated at the Intercontinental Exchange (ICE) market in New York. Similarly, wheat imports prices paid by Egypt, the world's largest wheat importer, are linked with wheat futures prices such as those negotiated at the Chicago Board of trade (CBOT) or Euronext/Matif in Paris (Janzen and Adjemian, 2017). Hence, the benefit of specializing in cash crop production, and the use of revenues to import food, hinges on the interaction of cash crop and staple food futures prices. High exports revenues can help alleviate partially, or fully, the burden associated with food import bills during periods of high international food prices. The extent of the contribution depends on several factors, which include the contribution of cash crop earnings to total export revenues, the price elasticities of international demand and supply for cash crops, and currency movements.

Whereas the available research into the volatility dynamics between cash crop and staple food international prices is relatively limited, studies using GARCH methodology to assess the interdependence among markets, including agriculture, are quite prolific. For example, Vivian and Wohar (2012) use a GARCH approach to examine the volatility interaction among a sample of 28 commodities and find significant volatility linkages and volatility persistence even after taking structural breaks into account. Using a BEKK and a dynamic conditional correlation (DCC) trivariate GARCH approach, Gardebroek and Hernandez (2013) find evidence of unidirectional volatility spillover running from maize to ethanol, but weak evidence of transmission from crude oil to maize market in the United States. An MGARCH with structural breaks is applied by Teterin et al. (2016) to explore the volatility dynamics between crude oil and maize future prices. Their results show that the volatility between crude oil and maize is less persistent when accounting for structural breaks in the mean and volatility. In a recent study, Al-Maadid et al. (2017) conclude that there are significant volatility spillover effects between energy and food markets, with the interaction greater during the 2006 food crisis and the 2008 financial crisis. Other studies using a GARCH method to examine price volatility among various commodities include those by Chang and Su (2010), Ji and Fan (2012), Harri and Hudson (2009), de Nicola et al. (2016), and TrujilloBarrera et al. (2012).

A growing number of studies looking at agricultural price volatility have been using waveletbased techniques. Although these techniques are common in the fields of physics, medicine, and mathematics, the expansion of their application to economics and finance is a quite recent phenomenon. The advantage of this approach is that it allows a decomposition of the main components of a price series to gain additional insights into the underlying factors shaping their movements (Percival et al., 2004). For example, Filip et al. (2016) apply a wavelet analysis to study the linkages between the price of feedstocks and ethanol in both Brazil and the United States. Their results show that feedstock prices lead those of ethanol. Kristoufek et al. (2016) report 
similar results using a wavelet coherence approach. Mensi et al. (2017) combine a wavelet and copula method to examine the interaction between implied volatility indices for oil, wheat, and maize and find evidence of asymmetric tail dependence among the selected commodities. Also, using a wavelet approach to disentangle the interaction between commodity and credit markets in sub-Saharan Africa, Ftiti et al. (2016) find a strong relationship over long timescales, confirming that the credit market is affected by persistent commodity shocks. Power and Turvey (2010) use a wavelet method to study the volatility interaction among 14 commodities, and Pal and Mitra (2017) using a wavelet-based methodology find that world food prices comove with crude oil prices, with the latter leading world food quotations.

With increasing evidence linking the market performance of equities to changes in commodity prices, several studies analyze the interaction between the financial market and commodities, including agriculture. These studies provide empirical evidence explaining the comovement between financial markets and commodities. The use of GARCH-based techniques in these studies is very common. For example, Mensi et al. (2013) examine the volatility integration between energy, food, gold, and beverages price indices, and the U.S. S\&P 500 index. Their results show significant return and volatility transmission across markets. Gao and Liu (2014) use a bivariate GARCH model to investigate the volatility interdependence between the S\&P 500 index and a sample of commodities, and Nazlioglu et al. (2013) look at the volatility transmission between crude oil and agricultural commodity markets, evidencing significant mean return and volatility integration. Other studies examining the linkages between financial markets and commodities include those by Olson et al. (2014), Park and Ratti (2008), Awartani and Maghyereh (2013), El Hedi Arouri et al. (2011), Malik and Ewing (2009), Diebold and Yilmaz (2012), Amatov and Dorfman (2017), and Grosche and Heckelei (2016).

\section{Methodology and data}

\subsection{Wavelet analysis}

Wavelet analysis is used to decompose a signal into its main components, enabling the possibility to focus on specific frequencies (Percival et al., 2004). In contrast to the Fourier transform, wavelet transform combines information on both time and frequency domains, allowing us to track timewise particular frequencies (Mensi et al., 2017). A wavelet transform is based on the mathematical operation of convolution, which specifies that the integral of the product of two functions, one of which is reversed and shifted, produces a third function that has similar features as the shifted and reversed function (Torrence and Compo, 1998). The wavelet transform is based on two specific functions: (1) the father wavelet, $\Phi(t)$, and (2) the mother wavelet, $\Psi(t)$. A series of wavelets called daughter wavelets, $\Psi_{u, s}(t)$, can be built by simply scaling and translating (shifting) $\Psi(t)$ :

$$
\Psi_{u, s}(t)=\frac{1}{\sqrt{s}} \Psi\left(\frac{t-u}{s}\right),
$$

where $\frac{1}{\sqrt{s}}$ is a normalization factor ensuring unit variance of the wavelet (i.e., $\left\|\Psi_{u, s}(t)\right\|^{2}=1$ ), and $u$ and $s$ are the location and scaling parameters, respectively (Crowley, 2005). The scaling parameter controls for the length of the wavelet and is related to the frequency of the input signal such that a larger (lower) value implies the wavelet will correlate with the low (high) frequencies contained in the time series. The term $u$ determines the location of the wavelet in the time domain. A number of wavelets have been developed to capture specific frequency characteristics of time series, and these include the Daubechies, Haar, Morlet, and Mexican hat. There are two types of wavelet transforms that are widely used in the literature: (1) the discrete wavelet transform (DWT) and (2) the continuous wavelet transform (CWT) (Crowley, 2005). The DWT is suitable for data compression and noise reduction, whereas the CWT is useful for smooth extraction of frequencies. Mother wavelets have to satisfy two main conditions: (1) zero mean 
(i.e., $\int_{-\infty}^{\infty} \Psi(t) d t=0$ ) and (2) unit energy (localized in time or space; i.e., $\int_{-\infty}^{\infty} \Psi^{2}(t) d t=1$ ). In addition, wavelets have to satisfy the admissibility condition, which guarantees a reconstruction of the original time series from its wavelet transform using the inverse transform (Shalini and Prasanna, 2016). For this article, we use the DWT, given the flexibility it offers in denoising time series (Crowley, 2005), but also because it produces a minimum number of coefficients necessary to reconstruct a series. Given its parsimonious nature, the DWT has wide applications (Moya-Martínez et al., 2015). To minimize the boundary effects at the extremities of time series when applying the DWT, we use the periodic decomposition often done in similar studies. Based on the DWT, any time series can be described as a linear combination of father and mother wavelets (Mensi et al., 2017):

$$
X(t)=\sum_{k} s_{j, k} \Phi_{j, k}(t)+\sum_{k} d_{j, k} \Psi_{j, k}(t)+\ldots+\sum_{k} d_{1, k} \Psi_{1, k}(t),
$$

where $j$ represents the multiresolution, or scale level, and $k$ depicts the number of coefficients at each scale level. Further, $s_{j, k}$ and $d_{j, k}$ are the scaling (or smooth) and detail (or wavelet) coefficients, respectively, and can be expressed as

$$
\begin{gathered}
s_{j, k}=\int X(t) \Phi_{j, k}(t) d t, \text { and } \\
d_{j, k}=\int X(t) \Psi_{j, k}(t) d t, \text { for } j=1,2, \ldots, j .
\end{gathered}
$$

The detail coefficient $d_{j, k}$ captures the high frequencies contained in the input signal, or time series, and the scale coefficient $s_{j, k}$ captures the smooth part, or the long-term trend, of the input function (Moya-Martínez et al., 2015). The original input function $X(t)$ can be reconstructed as a linear combination of the calculated coefficients (Mensi et al., 2017):

$$
X(t)=S_{j}(t)+D_{j}(t)+D_{j-1}(t)+\ldots+D_{1}(t),
$$

with the smooth, or approximation, components of the time series represented by $S_{j}=\Sigma_{k} S_{j, k} \Phi_{j, k}(t)$ and the details components of the series specified as $D_{j}=\Sigma_{k} d_{j, k} \Psi_{j, k}(t)$. In practice, a wavelet with some desired properties is chosen and convoluted with a time series to extract the various frequencies that are contained in the series. It is then possible to rebuild the series by excluding, for example, certain frequencies. The reconstruction of a time series using the DWT approach most often relies on Mallat's pyramid algorithm (Mallat, 1989), which consists of applying a series of low-pass and high-pass filters. Explicitly, a time series, $X(t)$, is convolved with high-pass and low-pass filters to extract the detail, $D_{1}(t)$, and approximation, $S_{1}(t)$, components of the series. Then $S_{1}(t)$ becomes the input for the subsequent iteration phase to derive $D_{2}(t)$ and $S_{2}(t)$. This iterative process is repeated until the desired decomposition level $j$ is achieved (Crowley, 2005).

Denoising a series is one of the most common applications of wavelet analysis and involves selecting a threshold value $\lambda$, which is then used to filter the derived wavelet coefficients. There are two types of thresholding: (1) hard thresholding, where wavelet coefficients with the absolute value less than the threshold are set to zero, and (2) soft thresholding, where the absolute values of the wavelet coefficients above $\lambda$ are shrunk (Haven, Liu, and Shen, 2012). We define $\lambda$ according to Donoho (1995) such that $\lambda=\sqrt{2 \sigma^{2}} \log (N)$, where $N$ represents the length of the signal, and $\sigma$ stands for the variance of the noise, which is estimated by computing the variance of the wavelet coefficients derived from the first decomposition level. ${ }^{7}$ Therefore, the threshold level increases with the volatility of the time series. The denoised time series is then constructed by substituting the detailed wavelet coefficients derived through the DWT with the "thresholded" wavelet coefficients.

\footnotetext{
${ }^{7}$ The Donoho approach is also referred to as the universal thresholding. Other thresholding methods include visu shrink, sure shrink, and Bayes shrink.
} 
In this article, we use the Daubechies "extremal phase wavelets" (Daubechies, 1992), as previous studies have shown that the Daubechies extremal phase wavelets are appropriate for financial data, and implement the DWT to denoise the cash and staple food index series. Typically, denoising the price indices implies removing those wavelet coefficients that do not contribute significantly to the signal. In terms of our index series, noise may represent short-term speculative behavior, scalping, herd behavior, outliers, or irrational price movements (Gardebroek and Hernandez, 2013). Daily observations such as futures prices typically contain a lot of noise, which does not necessarily contribute to the underlying movement in prices.

\subsection{GARCH approach}

As highlighted in the literature review, the MGARCH model is widely applied in the analysis of integration between markets. In this article, we study the volatility spillover between cash crop futures price index and staple food futures price index at an international level. The basis for constructing the indices is discussed later in Section 3.3. Our approach assumes that the variancecovariance matrix follows a BEKK-GARCH specification. The bivariate BEKK-GARCH model is expressed as

$$
A(L) r_{t}=\varepsilon_{t}
$$

and

$$
\varepsilon_{t} \mid \omega_{t-1} \sim N\left(0, H_{t}\right)
$$

where $A(L)$ is a polynomial matrix in the lag operator $L, r_{t}$ is a $2 \times 1$ daily return vector at time $t$, and $\varepsilon_{t}$ is a $2 \times 1$ vector of random errors representing the shocks, or innovations, at time $t . H_{t}$ is a $2 \times 2$ conditional variance-covariance matrix, given market information $\omega_{t-1}$ available at time $t-1$. Equation (6) represents the mean conditional equation and describes the impact of own and lagged shocks as well as lagged innovations in other markets on the conditional mean of a variable at time $t$. The order of the system can be selected on the basis of a standard information criterion (e.g., Akaike information criterion [AIC], Schwarz information criterion [SIC]).

With respect to the form that $H_{t}$ can take, it generally depends on the number of variables and the objective of the research. Often, when the number of variables is large, a less flexible MGARCH specification is chosen. This is because model convergence during the estimation process is difficult to achieve if the number of variables is larger than three and, in particular, when exogenous variables are included (El Hedi Arouri et al., 2015). Convergence issues with higher model dimension can be limited by restrictive specifications such as the diagonal BEKKGARCH and the scalar BEKK-GARCH models. These parsimonious specifications reduce the computational complexity and facilitate model solution. The list of more flexible GARCH specifications is fairly exhaustive, and we only mention here the most commonly used models, which comprise the full BEKK-GARCH model, introduced by Engle and Kroner (1995); the constant conditional correlation-GARCH model, specified by Bollerslev (1990); the DCC-GARCH model of Engle (2002); and the vector autoregressive (VAR)-GARCH introduced by Ling and McAleer (2003).

Based on the model proposed by Engle and Kroner (1995), the conditional variance-covariance matrix of the BEKK-GARCH specification can be expressed as

$$
H_{t}=C_{0}^{\prime} C_{0}+A_{11}^{\prime} \varepsilon_{t-1} \varepsilon_{t-1}^{\prime} A_{11}+G_{11}^{\prime} H_{t-1} G_{11},
$$

or in matrix form as

$$
H_{t}=C_{0}^{\prime} C_{0}+\left[\begin{array}{ll}
a_{11} & a_{12} \\
a_{21} & a_{22}
\end{array}\right]^{\prime}\left[\begin{array}{ll}
\varepsilon_{1, t-1}^{2} & \varepsilon_{1, t-1}, \varepsilon_{2, t-1} \\
\varepsilon_{1, t-1,} \varepsilon_{2, t-1} & \varepsilon_{2, t-1}^{2}
\end{array}\right]\left[\begin{array}{ll}
a_{11} & a_{12} \\
a_{21} & a_{22}
\end{array}\right]+\left[\begin{array}{ll}
g_{11} & g_{12} \\
g_{21} & g_{22}
\end{array}\right]^{\prime} H_{t-1}\left[\begin{array}{ll}
g_{11} & g_{12} \\
g_{21} & g_{22}
\end{array}\right],
$$


where $C_{0}^{\prime} C_{0}$ represents the decomposition of the intercept matrix, with $C_{0}$ restricted to be a lower triangular matrix. The unrestricted $n \times n$ matrices $A$ and $G$ contain the own autoregressive conditional heteroskedasticity $(\mathrm{ARCH})$ and cross-market $\mathrm{ARCH}$ effects and the own GARCH and cross-market GARCH effects, respectively. With this specification, it is possible to trace the effect of innovations and volatility in one market and how they transmit to other markets. These estimates are contained in matrices $A$ and $G$. Expanding equation (8) yields the variance-covariance equations:

$$
\begin{aligned}
h_{11, t}= & c_{11}^{2}+a_{11}^{2} \varepsilon_{1, t-1}^{2}+2 a_{11} a_{21} \varepsilon_{1, t-1} \varepsilon_{2, t-1}+a_{21}^{2} \varepsilon_{2, t-1}^{2}+g_{11}^{2} h_{11, t-1}+2 g_{11} g_{21} h_{12, t-1}+g_{21}^{2} h_{22, t-1} \\
h_{12, t}= & c_{11} c_{21}+a_{11} a_{12} \varepsilon_{1, t-1}^{2}+\left(a_{21} a_{12}+a_{11} a_{22}\right) \varepsilon_{1, t-1} \varepsilon_{2, t-1}+a_{21} a_{22} \varepsilon_{2, t-1}^{2}+g_{11} g_{12} h_{11, t-1} \\
& +\left(g_{21} g_{12}+g_{11} g_{22}\right) h_{12, t-1}+g_{21} g_{22} h_{22, t-1} \\
h_{22, t}= & c_{21}^{2}+c_{22}^{2}+a_{12}^{2} \varepsilon_{1, t-1}^{2}+2 a_{12} a_{22} \varepsilon_{1, t-1} \varepsilon_{2, t-1}+a_{22}^{2} \varepsilon_{2, t-1}^{2}+g_{12}^{2} h_{11, t-1}+2 g_{12} g_{22} h_{12, t-1} \\
& +g_{22}^{2} h_{22, t-1} .
\end{aligned}
$$

With the assumption that error terms follow a multivariate standard normal distribution, the BEKK-GARCH models are estimated by maximizing the log-likelihood function using the Berndt, Hall, Hall, and Hausman (BHHH) algorithm. The conditional log-likelihood function $L$ for a sample of $T$ observations is

$$
\begin{gathered}
L(\theta)=\sum_{t=1}^{T} l_{t}(\theta), \text { with } \\
l(\theta)=-\log 2 \pi-\frac{1}{2} \log \left|H_{t}(\theta)\right|-\frac{1}{2} \varepsilon_{t}^{\prime}(\theta) H_{t}^{-1}(\theta) \varepsilon_{t}(\theta),
\end{gathered}
$$

where $\theta$ represents the vector of all the parameters to be estimated.

\subsection{Data}

Two price indices are produced to capture movements in cash crop and staple futures prices. The cash crop futures index is constructed by taking a weighted average of the daily closing futures prices realized at the ICE for sugar no. 11 (raw sugar; SB) futures, cocoa (CC) futures, coffee "C" (KC) futures, and cotton no. 2 (CT) futures. We first normalize the prices and use the daily traded volumes (number of contracts traded) as weights to derive the daily futures price index. We follow a similar procedure for the staple food futures prices, where we use the daily closing futures prices realized at the CBOT for corn (C1) futures, soybeans (SB1) futures, and wheat (W1) futures and use the respective traded volumes as weights. For both indices, daily futures prices and volume data are sourced from Bloomberg and cover the period of January 3, 1990, to August 30, 2016. All futures prices are historical first generic price series, and expiring active futures contracts are rolled to the next deferred contract after the last trading day of the front month. ${ }^{8}$

The choice of the commodities included in the two indices is based on a preanalysis that involves identifying the top exported cash crops and the top imported staple foods by the LIFDCs group. ${ }^{9}$ We then select those crops for which an international futures contract exists. On this basis, coffee, cocoa, cotton, and sugar futures prices are selected to represent the group

\footnotetext{
${ }^{8}$ Carchano and Pardo (2009) apply five different methodologies for rolling futures contracts, including the one we use in our article. They found that the choice of the rollover date does not induce significant differences between series. That is, the series preserve their general statistical characteristics regardless of the rollover selection criteria.

${ }^{9}$ The analysis uses the FAOSTAT database: http://www.fao.org/faostat/en/\#data.
} 
Figure 1. Daily movements of staple foods and cash crop price indices $(2010=1)$.

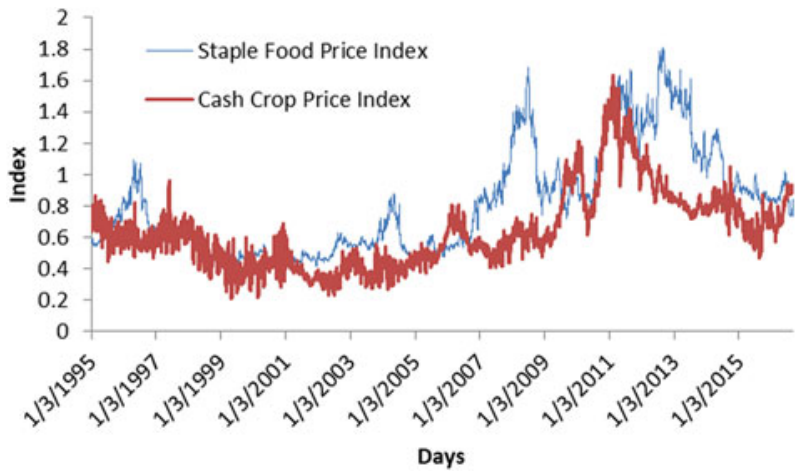

of cash crops, and wheat, corn, and soybeans futures prices are selected to characterize the staple food group. As with similar studies, the analysis is undertaken using the returns of the index series by taking the differences in the logarithm of two consecutive price indices. The choice of transforming the index series is determined by the fact that the cash crop and staple food indices are integrated at different orders. Both the augmented Dickey-Fuller (ADF) and the Phillips-Perron (PP) tests fail to reject the presence of unit root for the staple food index, whereas both tests reject the null hypothesis of nonstationarity for the cash crop index. Given that the indices are integrated at different orders - that is, staples being I(1) and cash crops I(0) - a vector error correction model (VECM) framework is not suitable in our case. Hence, a VAR is specified in returns in order to get consistent estimates. Figure 1 shows the daily movements of both cash and staple food price indices. The graph highlights the extent of the volatility that underpins both markets. ${ }^{10}$

\section{Descriptive statistics and results}

\subsection{Descriptive statistics}

The descriptive statistics of the price index return series are reported in Table 1. The statistics show that the food price index has the largest daily return and the lowest standard deviation, in comparison with the cash crop index. Overall, the series are asymmetric, with a small positive skewness, and have large kurtosis coefficients. The Jarque-Bera test statistics rejects the null hypothesis of normality for both price return indices. The ARCH test for heteroskedasticity points to the presence of the ARCH effect in both index series. Also, the Ljung-Box test for autocorrelation evidences the presence of autocorrelation. These results corroborate the use of an MGARCH model in assessing the volatility integration between cash crop and staple food markets. They are also in-line with the underlying characteristics of commodity price movements, notably volatility clustering, as described by Deaton and Laroque (1992). With respect to the stationarity of the series, ADF and the PP tests reject the null hypothesis of nonstationarity at the $1 \%$ level of significance. The unconditional correlation between cash and staple food price index using the Pearson coefficient is estimated to be 0.74 at the $5 \%$ level of significance.

\footnotetext{
${ }^{10}$ One critique of transforming a VAR in first differences is that it may lead to overdifferencing and thus induce noninvertibility in some series. As such, a VAR with differenced variables may be misspecified. We take the other view expressed in the literature, which shows that the cost of overdifferencing is not large, particularly when consideration is given to the properties of the model disturbances, within a stationary multivariate framework (see Damane, 2018; Maddala and Kim, 1998; Marcet, 2005; Plosser and Schwert, 1977). Hence, we use a VAR-BEKK-MGARCH in first differences with appropriate lag length and error structure.
} 
Table 1. Descriptive statistics of the price index returns

\begin{tabular}{|c|c|c|}
\hline & Staple Food Index Return & Cash Crop Index Return \\
\hline Mean (\%) & 0.0075 & 0.0053 \\
\hline Median (\%) & -0.0247 & -0.0117 \\
\hline Maximum & 22.3032 & 71.1149 \\
\hline Minimum & -19.4870 & -59.6080 \\
\hline Standard deviation (\%) & 2.3153 & 6.9209 \\
\hline Skewness & 0.1380 & 0.6922 \\
\hline Kurtosis & 8.6483 & 14.8098 \\
\hline Jarque-Bera & 17,081 & 50,470 \\
\hline$P$ value & 0.0000 & 0.0000 \\
\hline $\mathrm{Q}(14)$ & 153.5700 & 467.8300 \\
\hline$P$ value & 0.0000 & 0.0000 \\
\hline $\mathrm{ARCH}(14)$ & 175 & 1,176 \\
\hline$P$ value & 0.0000 & 0.0000 \\
\hline ADF & -59.0660 & -66.0250 \\
\hline$P$ value & 0.0100 & 0.0100 \\
\hline PP & -86.0580 & -104.3500 \\
\hline$P$ value & 0.0100 & 0.0100 \\
\hline
\end{tabular}

Notes: Q(14) refers to the Ljung-Box test for autocorrelation of order 14 . ARCH(14) is the Engle (1982) test for conditional heteroskedasticity of order 14 , and the Jarque-Bera test is used to test for normality. The augmented Dickey-Fuller (ADF) and the Phillips-Perron (PP) methods are used to test for nonstationarity of the index series. ARCH, autoregressive conditional heteroskedasticity.

\subsection{Results of the wavelet analysis}

As discussed in Section 3, we use the Daubechies "extremal phase wavelets" to decompose the series into approximated and detailed series. The Daubechies family of wavelets is used in finance and economics because of their desirable properties of ortho-normality, asymmetry, and higher number of vanishing moments (Daubechies, 1992). Figure 2 illustrates the decomposition exercise based on a multiresolution analysis (MRA) at various scales for both food and cash crop price indices. A maximum scale level $j$ of 12 is selected, which is standard in the literature, because previous studies have shown that moderate filters are appropriate for financial data (Gençay, Selçuk, and Whitcher, 2001, 2005; In and Kim, 2013). Note that, according to Nyquist's rule, half of the sample can be eliminated at each successive scale level. For illustrative purposes, we present three detailed series and one approximation series derived from the calculated values of the wavelet transform coefficients. A wavelet coefficient can be interpreted as the difference between two adjacent averages for a certain scale (Percival et al., 2004). Practically, it shows how the average of a particular series changes when considering various scales (e.g., 2 days, 20 days, or 360 days). Analyzing the change in the average of price series at different scales helps detect any possible trends, discontinuities, or abrupt changes in the series. In Figure 2, the highest scale level (frequency) component $\mathrm{d} 1$ corresponds to a time-scale (frequency) of $2^{1}=2$ days (daily effects), while d5 accounts for variations in a time-scale (frequency) of $2^{5}=32$ days. The coarser, or smoother, part of the series (S7) captures the trend. 

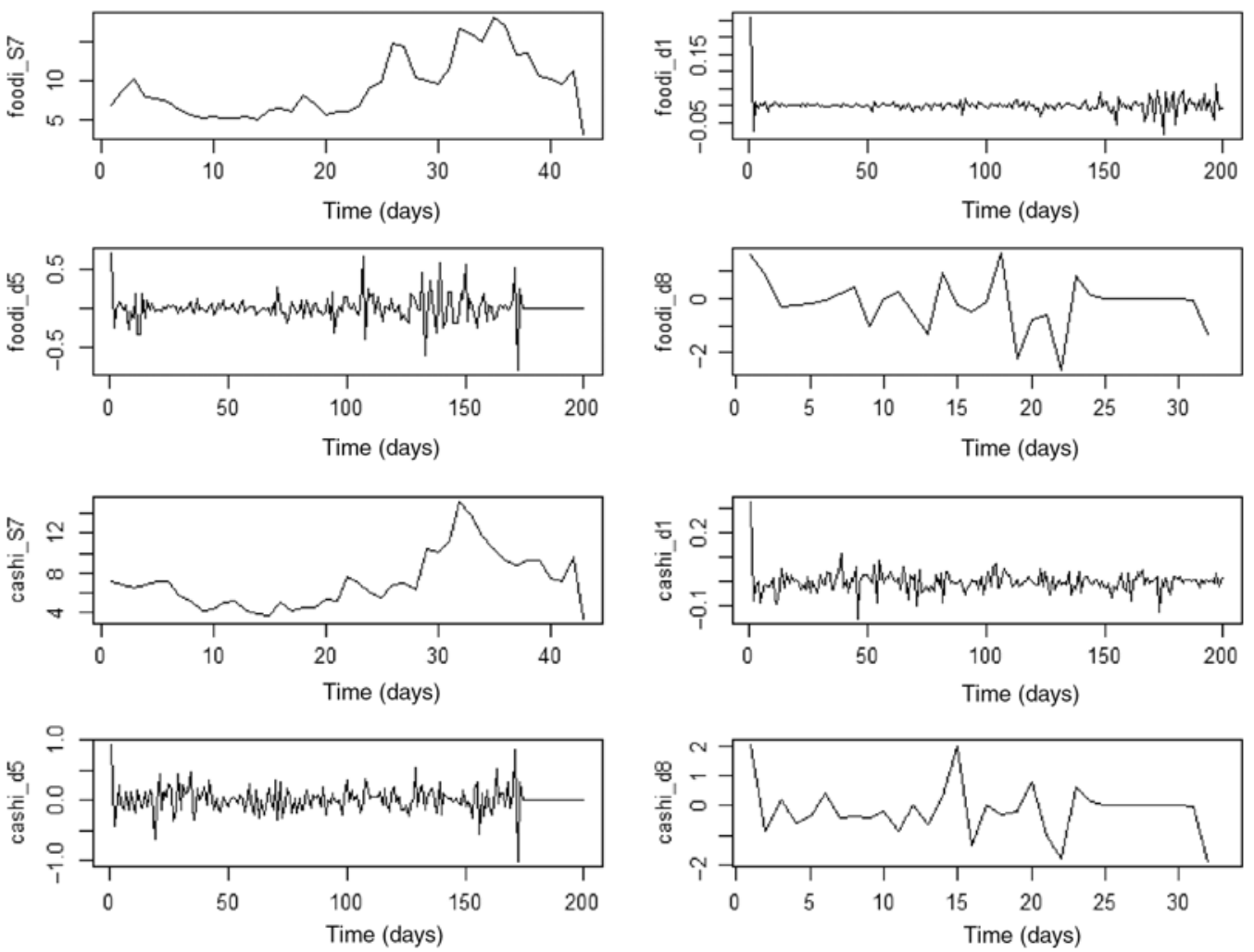

Figure 2. Wavelet decomposition results at selected scales for cash crop and staple food series. Note: "foodi" stands for food price index, and "cashi" represents the cash crop price index.

The MRA in Figure 2 suggests that the variations in the series are relatively heterogeneous across scales and time, with high fluctuations evidenced at finer-scale resolutions for both cash and staple food series. Some localized features are interesting to point out. For example, a stretch of high volatility toward the end of the sample is revealed for the staple food index, whereas there are marked variances at the start and toward the end of the sample for the cash crop price index, underpinned by large fluctuations in the value of the wavelet coefficients. The smooth series for the cash and staple food series (S7 in Figure 2) highlight the upward trend underlining both series up to their respective peak. Hence, the MRA suggests that the fluctuations in the decomposed series are heterogeneous across time and scales, implying that we can gain additional insights into the dynamics of the indices by considering their relationship at various scale levels. After obtaining the wavelet transform values, we proceed by denoising the series, as described in Section 3. Then, the series are reconstructed by adding to the trend, selected frequencies, or detail series, as described in equation (5). The selected scales (frequencies) are (1) low frequency $(d=9),(2)$ medium frequency $(\mathrm{d}=5)$, and (3) high frequency $(\mathrm{d}=1),{ }^{11}$ as illustrated in Figures 3 and 4.

It is also possible to quantify how much each scale contributes to the overall variability of the index series through scale-based variance decomposition, as in Percival et al. (2004). The

\footnotetext{
${ }^{11}$ In the DWT, the number of observations needs to be dyadic - that is, an integer power of two. We use business days, so that $d=9$ corresponds to $2^{9}=512$ days. We chose three scales, corresponding to short, medium, and longer term, for the sake of clarity and to simplify reference to the results in the context of the study.
} 


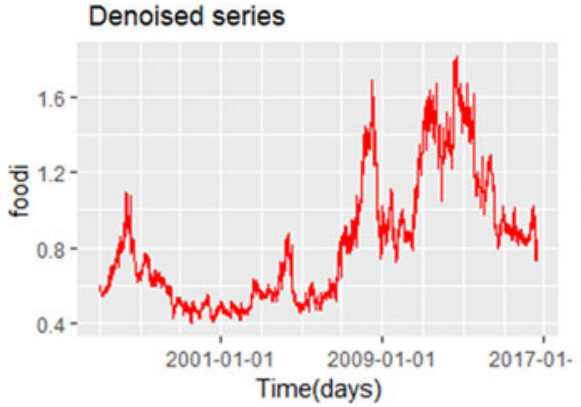

Medium Frequency

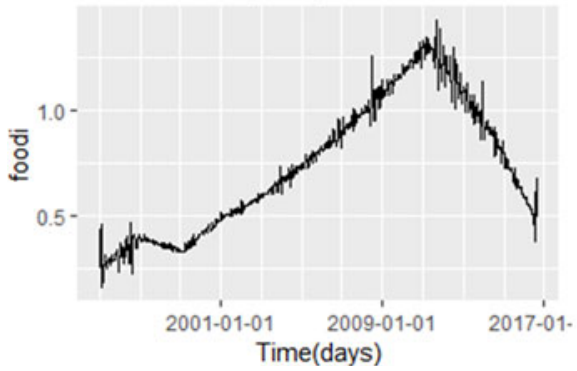

Low Frequency

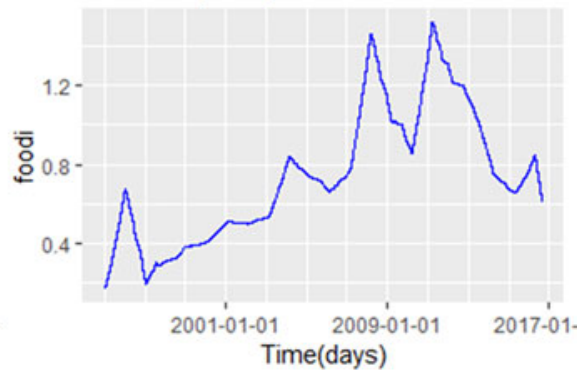

High Frequency

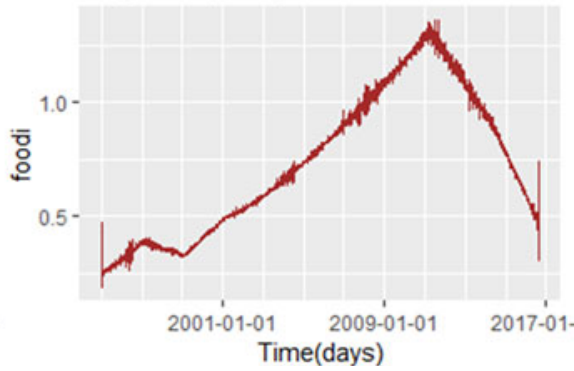

Figure 3. Reconstructed staple food price series at selected scales. Note: "foodi" stands for food price index.

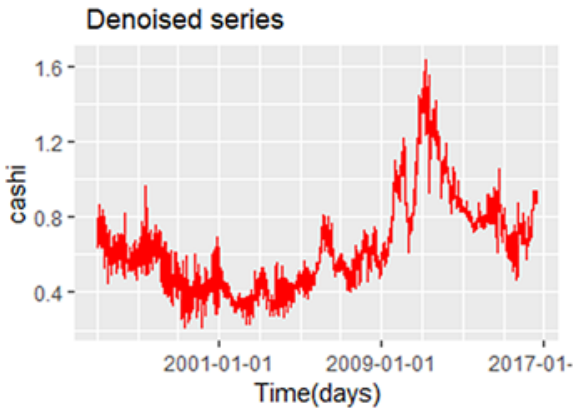

Medium Frequency

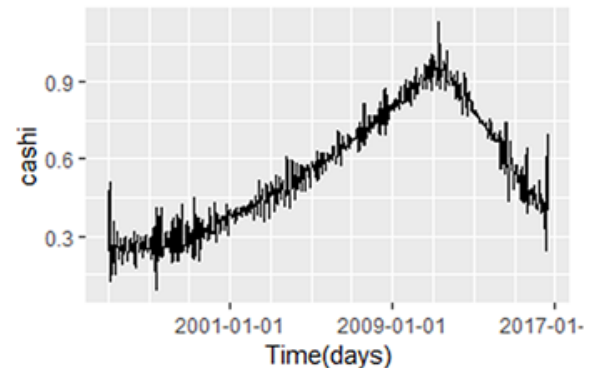

Low Frequency

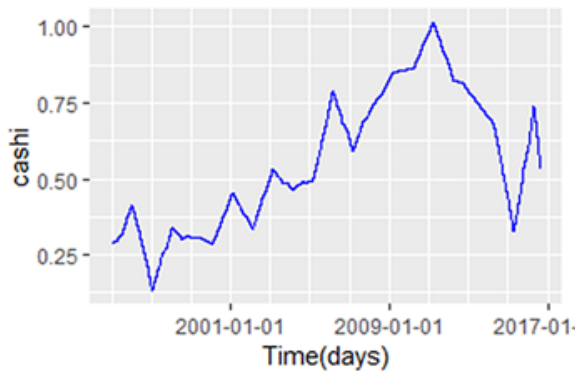

High Frequency

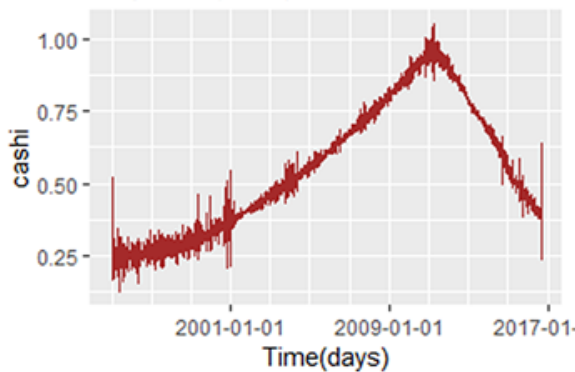

Figure 4. Reconstructed cash crop price series at selected scales. Note: "cashi" represents the cash crop price index. 
wavelet variance decomposition indicates that the largest contribution to the sample variance is accounted for by variations at the largest scale (long-run fluctuations) for both the cash crop and staple food indices. Hence, long-run variations have more weights on the series than short-run fluctuations.

In general, the results of the wavelet analysis show that the index series have common trends and volatility patterns, although differences in volatility prevail at specific scales. This suggests that the level of interdependence and the dynamics of volatility between cash crop and staple food price indices may vary depending on the considered timescale. As a result, we apply a BEKKGARCH model using the denoised series at various time-frequency domains to account for the heterogeneity in the variance dynamics. This is described in the next section.

\subsection{GARCH model}

Using the staple food and the cash crop return indices, we estimate four bivariate VAR-BEKKGARCH models. The first model uses the original series, whereas the other three models are applied to the denoised series but for different scale frequencies: low frequency (model 2), medium frequency (model 3), and high frequency (model 4). The VAR specification describes the conditional mean of the model, and the GARCH component explores the volatility interactions. We apply the AIC and SIC information criteria to identify the optimal lag order of the VAR system and run univariate GARCH for both index series to which we apply the same information criteria to examine the lag order for the GARCH component. The information criteria selects VAR(3) and $\operatorname{GARCH}(1,1)$ as the optimal specification. A comparative estimation of the log-likelihood values derived from other alternative lag specifications confirms the data are best characterized by a GARCH $(1,1)$ specification.

The estimation results are reported in Table 2. The ARCH terms $\left(\mathrm{a}_{1 \mathrm{i}}, \mathrm{a}_{2 \mathrm{i}}\right)$ indicate whether the conditional volatility is driven by lagged innovations, and the GARCH estimates $\left(g_{1 i}, g_{2 i}\right)$ show if the current conditional volatility is influenced by its lagged values, reflecting volatility persistence. In general, estimation results for the four pairwise bivariate $\operatorname{VAR}(3)$-BEKK-GARCH $(1,1)$ models reveal some similar patterns with respect to the estimated ARCH and GARCH coefficients. First, the coefficients are found to be statistically significant for most of the pairwise estimations. Second, the estimated values for the ARCH coefficients are generally lower than the GARCH estimates, implying that lagged shocks do not affect current conditional variance as much as lagged volatility values. The diagnostic tests carried out on the standardized residuals and squared standardized residuals show a significant reduction in $\mathrm{ARCH}$ effects and autocorrelation depicted in the return series (see Table 1), indicating that the estimated models are sufficiently flexible to describe the volatility dynamics between staples and crop returns.

Table 2 also reports estimations for the mean price return equations. Results indicate that, generally, the own autoregressive parameters for both staple food and cash crop return indices are found to be statistically significant, implying short-term predictability. Results also show that some cross-market returns parameters are found to be positive and statistically significant, but their number is much less than in the case of own mean spillover estimates. Also, we note that the information transmission flows mostly from the staple food to the cash markets, as shown by the number of significant coefficients capturing the effect of changes in staple food crop returns on cash crop returns. This result may in fact reflect the relatively greater liquidity in the staple food futures markets relative to cash crop futures markets.

The diagonal elements of matrix A (see equation 7), which captures own shocks, and the diagonal elements of matrix G, associated with own GARCH effect, are significant for most of the estimated models. That is, own news and past volatility movements affect the current conditional variance values. Also, a general assessment shows that the off-diagonal elements of matrix A and matrix $G$ are for most cases significant, but with some degree of variations, reflecting asymmetries in the dynamics. In terms of model 1 (i.e., original series), results are generally in-line with those 
Table 2. Estimates of VAR(3)-BEKK-GARCH(1,1) for staple food and cash crop price indices at various time-frequency domains

\begin{tabular}{|c|c|c|c|c|c|c|c|c|}
\hline & \multicolumn{2}{|c|}{ Model 1} & \multicolumn{2}{|c|}{ Model 2} & \multicolumn{2}{|c|}{ Model 3} & \multicolumn{2}{|c|}{ Model 4} \\
\hline & Food $(i=1)$ & Cash $(i=2)$ & Food $(i=1)$ & Cash $(i=2)$ & Food $(i=1)$ & Cash $(i=2)$ & Food $(i=1)$ & Cash $(i=2)$ \\
\hline \multicolumn{9}{|c|}{ Conditional mean } \\
\hline \multirow[t]{2}{*}{ Constant } & 0.0000 & 0.0000 & 0.0000 & 0.0000 & 0.00001 & 0.0000 & 0.0004 & 0.0003 \\
\hline & $(0.7989)$ & $(0.9604)$ & $(0.8992)$ & $(0.8217)$ & $(0.8997)$ & $(0.9849)$ & $(0.0570)$ & $(0.6238)$ \\
\hline \multirow[t]{2}{*}{ Food $(-1)$} & -0.1576 & 0.1314 & 1.1701 & 0.0011 & 1.0698 & -0.0024 & -1.2659 & 0.1042 \\
\hline & $(0.0000)$ & $(0.0008)$ & $(0.0000)$ & $(0.9573)$ & $(0.0000)$ & $(0.9374)$ & $(0.0000)$ & $(0.0037)$ \\
\hline \multirow[t]{2}{*}{$\operatorname{Cash}(-1)$} & 0.0104 & -0.3118 & 0.0122 & 1.1818 & -0.0076 & 1.0526 & -0.0012 & -1.3202 \\
\hline & $(0.0263)$ & $(0.0000)$ & $(0.5105)$ & $(0.0000)$ & $(0.2730)$ & $(0.0000)$ & $(0.7634)$ & $(0.0000)$ \\
\hline \multirow[t]{2}{*}{ Food $(-2)$} & -0.0554 & 0.0195 & -0.3225 & 0.0047 & -0.2752 & 0.0018 & -1.0645 & 0.0798 \\
\hline & $(0.0000)$ & $(0.6230)$ & $(0.0000)$ & $(0.8806)$ & $(0.0000)$ & $(0.9658)$ & $(0.0000)$ & $(0.0613)$ \\
\hline \multirow[t]{2}{*}{ Cash $(-2)$} & 0.0021 & -0.1367 & -0.0070 & -0.3321 & 0.0011 & -0.2792 & -0.0015 & -1.1122 \\
\hline & $(0.6672)$ & $(0.0000)$ & $(0.8017)$ & $(0.0000)$ & $(0.9092)$ & $(0.0000)$ & $(0.7777)$ & $(0.0000)$ \\
\hline \multirow[t]{2}{*}{ Food $(-3)$} & 0.0144 & 0.0216 & 0.1415 & -0.0071 & 0.0559 & -0.0021 & -0.4570 & 0.0715 \\
\hline & $(0.2880)$ & $(0.5826)$ & $(0.0000)$ & $(0.7330)$ & $(0.0001)$ & $(0.9450)$ & $(0.0000)$ & $(0.0281)$ \\
\hline \multirow[t]{2}{*}{$\operatorname{Cash}(-3)$} & 0.0069 & -0.0719 & -0.0067 & 0.1373 & 0.0042 & 0.0649 & -0.0065 & -0.5151 \\
\hline & $(0.1394)$ & $(0.0000)$ & $(0.7156)$ & $(0.0000)$ & $(0.5446)$ & $(0.0000)$ & $(0.1118)$ & $(0.0000)$ \\
\hline \multicolumn{9}{|c|}{ Conditional variance-covariance } \\
\hline \multirow[t]{2}{*}{$c_{i 1}$} & -0.0062 & & 0.0000 & & -0.0010 & & -0.0008 & \\
\hline & $(0.0000)$ & & $(0.0005)$ & & $(0.0000)$ & & $(0.0000)$ & \\
\hline \multirow[t]{2}{*}{$\mathrm{c}_{\mathrm{i} 2}$} & & -0.0002 & & 0.0000 & & -0.0006 & & 0.0028 \\
\hline & & $(0.7099)$ & & $(0.0269)$ & & $(0.0000)$ & & $(0.0000)$ \\
\hline \multirow[t]{2}{*}{$\mathrm{a}_{1 \mathrm{i}}$} & -0.3569 & 0.0046 & 0.6107 & 0.1825 & 1.6485 & 0.0678 & -0.2557 & -0.6631 \\
\hline & $(0.0000)$ & $(0.7483)$ & $(0.0000)$ & $(0.0000)$ & $(0.0000)$ & $(0.0000)$ & $(0.0000)$ & $(0.0000)$ \\
\hline
\end{tabular}


Table 2. (Continued)

\begin{tabular}{|c|c|c|c|c|c|c|c|c|}
\hline \multirow[b]{2}{*}{$a_{2 i}$} & \multicolumn{2}{|c|}{ Model 1} & \multicolumn{2}{|c|}{ Model 2} & \multicolumn{2}{|c|}{ Model 3} & \multicolumn{2}{|c|}{ Model 4} \\
\hline & -0.0077 & -0.2607 & 0.2019 & 1.9197 & 0.0134 & 1.5411 & -0.0147 & 0.4915 \\
\hline & $(0.0380)$ & $(0.0000)$ & $(0.0000)$ & $(0.0000)$ & $(0.0089)$ & $(0.0000)$ & $(0.0000)$ & $(0.0000)$ \\
\hline \multirow[t]{2}{*}{$g_{1 i}$} & 0.8997 & 0.1050 & 0.0303 & 0.3049 & 0.4068 & -0.0102 & -0.9685 & 0.0603 \\
\hline & $(0.0000)$ & $(0.0174)$ & $(0.0010)$ & $(0.0000)$ & $(0.0000)$ & $(0.5044)$ & $(0.0000)$ & $(0.0000)$ \\
\hline \multirow[t]{2}{*}{$g_{2 i}$} & 0.0017 & -0.9681 & 0.8198 & 0.4907 & -0.0909 & -0.5653 & -0.0059 & -0.8627 \\
\hline & $(0.8324)$ & $(0.0000)$ & $(0.0000)$ & $(0.0000)$ & $(0.0000)$ & $(0.0000)$ & $(0.0000)$ & $(0.0000)$ \\
\hline \multicolumn{9}{|l|}{ Diagnostic tests } \\
\hline AIC & $-21,799.5600$ & & $-75,342.1200$ & & $-47,452.4000$ & & $-28,805.3100$ & \\
\hline LB & 26.9200 & $97.3560^{*}$ & $1,104.4000^{*}$ & $720.1400^{*}$ & $5,249.7000^{*}$ & $3,748^{\star}$ & $1,332^{*}$ & $1,554.9000^{*}$ \\
\hline $\mathrm{LB}^{2}$ & 28.6570 & 36.3710 & 14.5900 & 5.5227 & $1,163.3000^{*}$ & $1,076.1000^{*}$ & 79.6930 & $5,157.8000^{*}$ \\
\hline LM (ARCH) & 24.9390 & 36.6620 & 13.6070 & 4.9566 & $1,000.8000^{*}$ & $775.3000^{*}$ & $430.5400^{*}$ & $1,729.9000^{*}$ \\
\hline \multirow[t]{2}{*}{ Market correlation } & 1 & 0.0200 & 1 & 0.6300 & 1 & 0.3400 & 1 & 0.1200 \\
\hline & 0.0200 & 1 & 0.6300 & 1 & 0.3400 & 1 & 0.1200 & 1 \\
\hline
\end{tabular}

Notes: A bivariate model VAR(3)-full-BEKK-GARCH(1,1) model is estimated for each model from January 2, 1990, to August 28, 2016. The information criteria AIC (Akaike information criterion) and SIC (Schwarz information criterion) were used to select the optimal lag order for the VAR model and the GARCH specification. Model 1: original series; model 2: low frequency; model 3: medium frequency; and model 4: high frequency. $L B$ and $\mathrm{LB}^{2}$ are the Ljung-Box $Q$-statistic for standardized and standardized square residuals, respectively. $P$ values reported in parentheses. Asterisk (*) stands for significant at the standard $5 \%$ level.

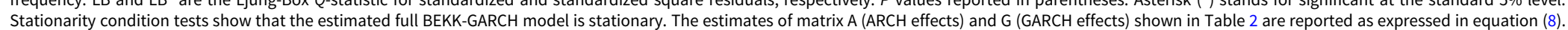

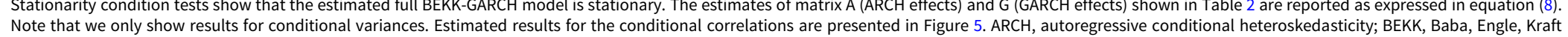
and Kroner; GARCH, generalized autoregressive conditional heteroskedasticity; VAR, vector autoregressive. 
obtained with the other models. For the staple food and cash crop equations, own ARCH and own GARCH terms are highly significant. In absolute terms, estimates of the ARCH coefficients are generally found to be much smaller than those obtained for the GARCH component, implying larger effects of past conditional variances than lagged innovations on current conditional variances.

For the low frequency model (i.e., long run), results indicate that the current conditional variance for cash crop return indices depends on their own ARCH and own GARCH terms, meaning that market volatility of cash crops can generally be predicted on the basis of past shocks and past variance. However, in contrast to model 1, the own ARCH effect is found to be larger than the own GARCH effect, suggesting that unexpected shocks play a much more important role in driving variability of staple returns at low frequencies. Likewise, the own ARCH estimate for staples and cash crop equations are found to be greater than the own GARCH effects for the medium-frequency model. In the case of the high-frequency model, the own GARCH effect is larger than the own ARCH effect for both the staple food and cash crop equations, in-line with the outcome obtained with model 1 . That is, at high frequencies, the conditional variances of cash crop and staple food returns are influenced by their respective past variances more so than unexpected news.

We now turn our attention to volatility transmission between staple food and cash crops, which is captured by the cross-estimates of ARCH and GARCH terms. Overall, there is significant volatility transmission between staple foods and cash crops as evidenced by the number of significant cross-effects terms estimated for the various pairwise systems. We note that the cross-market GARCH estimates are generally much larger than those of the cross-market $\mathrm{ARCH}$ effects. This is an indication that the conditional volatility of cash crop (staple food) markets is largely influenced by periods of volatility in the staple food (cash crop) markets rather than by the effects of lagged price return innovations in the staple food (cash crop) markets. Specifically, the GARCH cross-market effects are all statistically significant, with the exception of model 1, where past volatility in the cash market is statistically insignificant in the staple food market, and the medium-frequency model, where the past volatility in the food market is statistically insignificant in the cash market. On the other hand, the cross-market ARCH effects are all statistically significant, with the exception of model 1 , where past innovations in the staples market do not show a statistically significant influence on the volatility of cash crop returns. Overall, the results show that the absolute values of the estimated cross-market GARCH and $\mathrm{ARCH}$ estimates are generally higher and statistically significant in the low-frequency case than for the other frequency models, suggesting that the level of volatility interdependence between cash crop and staple returns is much stronger at lower frequencies. Further, the low-frequency model yields the largest Pearson correlation estimates, reflecting a tighter interdependence in the long run. The fact that the conditional correlations are larger at lower frequencies may suggest that external factors common to both markets, such as macroeconomic variables and world energy prices, explain the larger correlation in the long run. In the short run, commodityspecific factors (e.g., supply shocks affecting sugar crops) dominate movements in prices, a feature that underlines the lower conditional correlation between staples and cash crops. These results are also corroborated by the estimated conditional correlations, which indicate that the correlation at lower frequency is mostly positive and increasing in periods of high commodity prices (see Figure 5). Figure 5 also shows that as the frequency increases from low to high, the conditional correlation between staple and cash crop markets weakens. As mentioned, weaker volatility integration may be attributed to the influence of commodity-specific factors rather than common factors across staples and cash crops.

Estimation results also show that the cross-market values associated with the staple foods are generally larger than those relevant to cash crops. This means that information coming from the food markets influences cash crop markets to a larger extent than in the opposite direction, which could reflect the effect of greater liquidity underlying the staple food futures. The implication for 

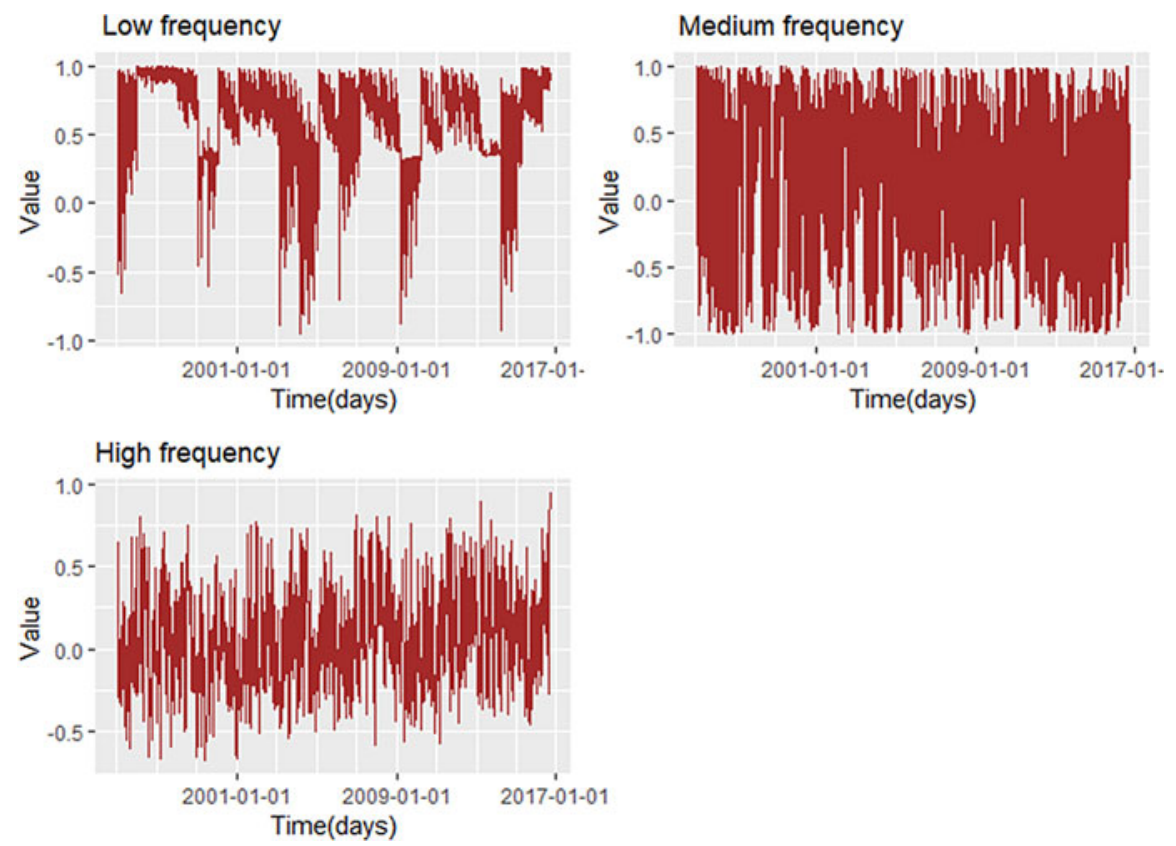

Figure 5. Estimated conditional correlation between the cash crop price index and the staple food price index at various time-frequency domains.

LIFDCs is that market information relevant to staple foods affects ultimately the variability of cash crop earnings. Despite the bidirectional nature of the relationship, both the own GARCH and own ARCH effects are found mostly larger in magnitude than the cross effects, highlighting the dominant role of intrinsic market factors.

Figure 5 shows the estimated conditional correlations between staple food and cash crop return series at various timescales calculated following equation (10). The estimated values exhibit high volatility throughout the sample period, with values ranging between -0.5 and 0.5 , notably for the medium- and high-frequency scales. In the case of the low-frequency model, conditional correlations fluctuate between 0.5 and 1, with occasional and abrupt changes mostly toward the negative values and periods of upward or downward trends.

Relatively high conditional correlation values associated with low-frequency scale implies that cash crop sales are a good hedge against increases in staple food import bills and can contribute to limiting current account instability in the long run, more so than in the short term. The extent to which export earnings offset current account deficits because of import bills depends on the elasticity of cash crop markets. The smaller the elasticity, the larger the increase in export earnings resulting from higher prices. What do these results mean for a country like Burundi, which relies on cash crop exports and imports of staple foods? Strong and positive conditional correlation between cash crop and staple food markets means that the government can evaluate more accurately its financial needs in the face of current account imbalances because of import bills by taking into consideration the fact that revenues from cash crop exports can reduce funding requirements and, hence, borrowing costs. Second, the government can also use price information relevant to international staple foods in the design and planning of investment strategies for the cash crop subsector, given the linkages between both commodity subsectors. For example, information on staple food price prospects can be utilized to strengthen the robustness of national cash crop price projections. 


\section{Conclusions and implications}

The analysis carried out in this article examines the volatility interaction between staple food and cash crop futures price returns. The dynamics between these commodity groups is relevant for developing countries that depend on cash crop export earnings to address current account imbalances and sustain food imports. We apply a BEKK-GARCH framework supplemented by a wavelet analysis to locate precisely marked periods of volatility and changes in the dynamics at different time horizons.

Estimation results show that the GARCH and ARCH elements associated with the staple foods exhibit, for the most cases, larger absolute values than their corresponding elements related to cash crops. This implies that the information transmission takes place mostly from staple foods to the cash crop markets at the international level. When the GARCH framework is applied at different timescales, based on the wavelet transform analysis, the outcome reveals that the relationship between cash crop and staple foods is the strongest at the lower-frequency scale. The estimated conditional correlations for the lower-frequency model are mostly positive, with marked periods of upward and downward trends. Several studies attribute this synchronized behavior to the financialization of commodity markets, as investors seek to diversify market risks (Basak and Pavlova, 2016; Grosche and Heckelei, 2016). In the long run, however, comovement between staple food and cash crop markets can reflect changes in factor input costs, notably labor costs.

The results of our analysis convey some implications from both an investment and policymaking perspective. Because the correlation is found relatively higher in the long run, with significant cross-market effects, investors cannot use cash crop assets as a hedging strategy against holding staple food assets. However, the significance of the cross-market effects means that they can take into account information contained in staple food futures when predicting cash crop returns. From a policy perspective, the results imply that cash crop exports are a good hedge against rises in staple food import bills in the long run and can contribute to reducing current account instability. This is because higher cash crop prices imply higher export earnings, given the inelastic nature of international cash crop markets.

These results highlight the importance of the cash crop subsector as an automatic consumption smoother, in the face of increases in import bills. It is often argued, however, that developing countries should diversify away from commodity production and export. This reasoning is based on the observation that real commodity prices have been on a declining trend relative to the price of manufactures. The Prebisch-Singer hypothesis provides the theoretical background behind the decline in relative prices, which translates into deteriorating terms of trade for the developing countries (UNCTAD and FAO, 2017). Often, the recommended solution is to move away from the production and export of commodities, such as cash crops, and into more value-added products and services. The problem with this argument is that it is highly sensitive to the metrics used to derive real prices, in addition to the various issues related to trend estimation. Perhaps, the conclusion on whether to move away from commodity production and export should be looked at from several perspectives. As an example, the results of this article indicate that when comparing a cash crop price index relative to a staple food index, there is no obvious downward trend; in fact, the relationship between the indices seems to remain relatively steady in the long run, with prevailing short-lived peaks (see Figure A1 in the Appendix). Hence, when considering the movements of cash crop prices relative to staple foods, it appears that cash crop sales have a role to play in limiting the impact of higher staple food prices and the resulting current account instability. Perhaps better policy advice to cash-crop-producing developing countries would be to argue for more investment in the cash crop subsector so that it is more resilient and efficient, while at the same time, expanding the mix of exported products, particularly into more value-added products.

A number of conceptual and methodological aspects still require further investigation. First, although we apply a DWT to reconstruct the series into various timescales, the use of a CWT 
approach does not require the arbitrary selection of timescales and accounts endogenously for the presence of structural breaks. A CWT framework enables the measurement of the correlation between staples and cash crop returns in a continuous time-frequency domain. Future research could examine the interaction between cash crop and staples returns using CWT and compare the results with those obtained using a DWT method. Second, additional efforts are needed toward understanding the theoretical and empirical estimation of higher-dimension MGARCH models. Many of the statistical results still lack theoretical background to be generalized. Still, joint estimation of higher-dimension MGARCH models remains very interesting from a research aspect as it makes full use of the dynamics characterizing a system of variables. Finally, for these results to be translated at the country level, an assessment of the transmission of futures prices to export prices and import prices is warranted. This will help anticipate the extent to which a country's cash crop export earnings can cover for food import bills given the volatile nature of international agricultural commodity markets.

Acknowledgements. The authors would like to thank the anonymous reviewers of this paper for constructive comments that helped improve the quality and content.

Financial support. This research was partially funded by European Union's Horizon 2020 research project SUSFANS under grant agreement no. 633692 .

Conflicts of interest. None.

\section{References}

Al-Maadid, A., G.M. Caporale, F. Spagnolo, and N. Spagnolo. "Spillovers between Food and Energy Prices and Structural Breaks." International Economics 150, 1(2017):1-18.

Amatov, A., and J.H. Dorfman. "The Effects on Commodity Prices of Extraordinary Monetary Policy." Journal of Agricultural and Applied Economics 49, 1(2017):83-96.

Awartani, B., and A.I. Maghyereh. "Dynamic Spillovers between Oil and Stock Markets in the Gulf Cooperation Council Countries.” Energy Economics 36, 1(2013):28-42.

Basak, S., and A. Pavlova. "A Model of Financialization of Commodities." Journal of Finance 71, 4(2016):1511-56.

Bollerslev, T. "Modelling the Coherence in Short-Run Nominal Exchange Rates: A Multivariate Generalized Arch Model." Review of Economics and Statistics 72, 3(1990):498-505.

Carchano, Ó., and A. Pardo. "Rolling over Stock Index Futures Contracts.” Journal of Futures Markets 29, 7(2009):684-94.

Chang, T.-H., and H.-M. Su. "The Substitutive Effect of Biofuels on Fossil Fuels in the Lower and Higher Crude Oil Price Periods." Energy 35, 7(2010):2807-13.

Chen, Y., K. Rogoff, and B. Rossi. "Predicting Agri-Commodity Prices: An Asset Pricing Approach." Working Paper No. UWEC-2010-02, Seattle: University of Washington, Department of Economics, 2010.

Crowley, P.M. “An Intuitive Guide to Wavelets for Economists.” SSRN Scholarly Paper No. ID 787564, Rochester, NY: Social Science Research Network, 2005.

Damane, M. "The Macroeconomic Impact of Shocks in the US Federal Funds Rate on the Republic of South Africa: An SVAR Analysis.” Modern Economy 9, 4(2018):796-829.

Daubechies, I. "Introduction; Preliminaries and Notation." Ten Lectures on Wavelets. Philadelphia, PA: Society for Industrial and Applied Mathematics, 1992, pp. vii-xix.

Deaton, A., and G. Laroque. "On the Behaviour of Commodity Prices.” Review of Economic Studies 59, 1(1992):1-23.

de Nicola, F., P. De Pace, and M.A. Hernandez. "Co-movement of Major Energy, Agricultural, and Food Commodity Price Returns: A Time-Series Assessment.” Energy Economics 57, 1(2016):28-41.

Diebold, F.X., and K. Yilmaz. "Better to Give than to Receive: Predictive Directional Measurement of Volatility Spillovers." International Journal of Forecasting 28, 1(2012):57-66.

Donoho, D.L.. "De-noising by Soft Thresholding." IEEE Transactions on Information Theory 41, 3(1995):613-27.

El Hedi Arouri, M., J. Jouini, and D.K. Nguyen. "Volatility Spillovers between Oil Prices and Stock Sector Returns: Implications for Portfolio Management." Journal of International Money and Finance 30, 7(2011):1387-405.

El Hedi Arouri, M., A. Lahiani, and D.K. Nguyen. "World Gold Prices and Stock Returns in China: Insights for Hedging and Diversification Strategies.” Economic Modelling 44, 1(2015):273-82.

Engle, R. "Dynamic Conditional Correlation: A Simple Class of Multivariate Generalized Autoregressive Conditional Heteroskedasticity Models." Journal of Business and Economic Statistics 20, 3(2002):339-50. 
Engle, R.F. "Autoregressive Conditional Heteroscedasticity with Estimates of the Variance of United Kingdom Inflation." Econometrica 50, 4(1982):987-1007.

Engle, R.F., and K.F. Kroner. "Multivariate Simultaneous Generalized ARCH.” Econometric Theory 11, 1(1995):122-50.

Fattouh, B., L. Kilian, and L. Mahadeva. "The Role of Speculation in Oil Markets: What Have We Learned So Far?." Discussion Paper No. 8916, London: Center for Economic Policy Research, 2012.

Filip, O., K. Janda, L. Kristoufek, and D. Zilberman. "Dynamics and Evolution of the Role of Biofuels in Global Commodity and Financial Markets." Nature Energy 17, 1(2016):35-105.

Food and Agriculture Organization (FAO). Commodity Market Review 2003-2004. Rome: FAO, Trade and Markets Division, 2004.

Food and Agriculture Organization (FAO). Medium-Term Prospects for RAMHOT Products. Rome: FAO, Trade and Markets Division, 2016.

Ftiti, Z., S. Kablan, and K. Guesmi. "What Can We Learn about Commodity and Credit Cycles? Evidence from African Commodity-Exporting Countries.” Energy Economics 60, 1(2016):313-24.

Gao, L., and L. Liu. "The Volatility Behavior and Dependence Structure of Commodity Futures and Stocks." Journal of Futures Markets 34, 1(2014):93-101.

Gardebroek, C., and M.A. Hernandez. "Do Energy Prices Stimulate Food Price Volatility? Examining Volatility Transmission between US Oil, Ethanol and Corn Markets.” Energy Economics 40, 1(2013):119-29.

Gençay, R., F. Selçuk, and B. Whitcher. An Introduction to Wavelets and Other Filtering Methods in Finance and Economics. First Edition. San Diego, CA: Academic Press, 2001.

Gençay, R., F. Selçcuk, and B. Whitcher. "Multiscale Systematic Risk." Journal of International Money Finance 24, 1(2005):55-70.

Ghosh, A.R., and J.D. Ostry. "Export Instability and the External Balance in Developing Countries." IMF Staff Papers 41, 2(1994):214-235.

Govereh, J., and T.S. Jayne. “Cash Cropping and Food Crop Productivity: Synergies or Trade-Offs?” Agricultural Economics 28, 1(2003):39-50.

Grosche, S.-C., and T. Heckelei. "Directional Volatility Spillovers between Agricultural, Crude Oil, Real Estate, and Other Financial Markets.” Food Price Volatility and Its Implications for Food Security and Policy. M. Kalkuhl, J. von Braun, and M. Torero, eds. Cham, Switzerland: Springer, 2016, pp. 183-205.

Hamilton, J.D., and J.C. Wu. "Effects of Index-Fund Investing on Commodity Futures Prices." International Economic Review 56, 1(2015):187-205.

Harri, A., and D. Hudson. "Mean and Variance Dynamics between Agricultural Commodity Prices and Crude Oil Prices." Paper presented at the Economics of Alternative Energy Sources and Globalization: The Road Ahead Meeting, Orlando, FL, November 15-17, 2009.

Haven, E., X. Liu, and L. Shen. "De-noising Option Prices with the Wavelet Method" European Journal of Operational Research 222, 1(2012):104-12.

In, F., and S. Kim. An Introduction to Wavelet Theory in Finance: A Wavelet Multiscale Approach. Singapore: World Scientific, 2013.

International Monetary Fund (IMF). Food and Fuel Prices-Recent Developments, Macroeconomic Impact, and Policy Responses: An Update. Washington, DC: IMF, 2008.

Irwin, S.H., and D.R. Sanders. "Index Funds, Financialization, and Commodity Futures Markets." Applied Economic Perspectives and Policy 33, 1(2011):1-31.

Janzen, J.P., and M.K. Adjemian. "Estimating the Location of World Wheat Price Discovery." American Journal of Agricultural Economics 99, 5(2017):1188-207.

Ji, Q., and Y. Fan. “How Does Oil Price Volatility Affect Non-Energy Commodity Markets?” Applied Energy 89, 1(2012):273-80.

Kristoufek, L., K. Janda, and D. Zilberman. "Comovements of Ethanol-Related Prices: Evidence from Brazil and the USA." GCB Bioenergy 8, 2(2016):346-56.

Ling, S., and M. McAleer. “Asymptotic Theory for a Vector ARMA-GARCH Model.” Econometric Theory 19, 2(2003):280310 .

Maddala, G.S., and I.M. Kim. Unit Roots, Cointegration, and Structural Change. Cambridge: Cambridge University Press, 1998.

Malik, F., and B.T. Ewing. "Volatility Transmission between Oil Prices and Equity Sector Returns." International Review of Financial Analysis 18, 3(2009):95-100.

Mallat, S.G. “A Theory for Multiresolution Signal Decomposition: The Wavelet Representation.” IEEE Transactions on Pattern Analysis and Machine Intelligence 11, 7(1989):674-93.

Marcet, A. “Overdifferencing VAR's is OK." Manuscript, Barcelona: Universitat Pompeu Fabra, 2005.

Maxwell, S., and A. Fernando. "Cash Crops in Developing Countries: The Issues, the Facts, the Policies." World Development 17, 11(1989):1677-708.

Mensi, W., M. Beljid, A. Boubaker, and S. Managi. "Correlations and Volatility Spillovers across Commodity and Stock Markets: Linking Energies, Food, and Gold.” Economic Modelling 32, 1(2013):15-22. 
Mensi, W., A. Tiwari, E. Bouri, D. Roubaud, and K.H. Al-Yahyaee. "The Dependence Structure across Oil, Wheat, and Corn: A Wavelet-Based Copula Approach Using Implied Volatility Indexes.” Energy Economics 66, 1(2017):122-39.

Mittal, A. “The 2008 Food Price Crisis: Rethinking Food Security Policies.” G-24 Discussion Paper No. 56, New York: United Nations, 2009.

Moya-Martínez, P., R. Ferrer-Lapeæa, and F. Escribano-Sotos. "Interest Rate Changes and Stock Returns in Spain: A Wavelet Analysis.” BRQ Business Research Quarterly 18, 2(2015):95-110.

Nazlioglu, S., C. Erdem, and U. Soytas. "Volatility Spillover between Oil and Agricultural Commodity Markets." Energy Economics 36, 1(2013):658-65.

Norton, R.D., and P.B. Hazell. Mathematical Programming for Economic Analysis in Agriculture. London: Collier Macmillan, 1986.

Olson, E., A.J. Vivian, and M.E. Wohar. "The Relationship between Energy and Equity Markets: Evidence from Volatility Impulse Response Functions.” Energy Economics 43, 1(2014):297-305.

Pal, D., and S.K. Mitra. "Time-Frequency Contained Co-movement of Crude Oil and World Food Prices: A Wavelet-Based Analysis.” Energy Economics 62, 1(2017):230-39.

Park, J., and R.A. Ratti. “Oil Price Shocks and Stock Markets in the U.S. and 13 European Countries." Energy Economics 30, 5(2008):2587-608.

Percival, D.B., M. Wang, and J.E. Overland. "An Introduction to Wavelet Analysis with Applications to Vegetation Time Series.” Community Ecology 5, 1(2004):19-30.

Plosser, C.I., and G.W. Schwert. "Estimation of a Non-Invertible Moving Average Process: The Case of Overdifferencing." Journal of Econometrics 6, 2(1977):199-224.

Power, G.J., and C.G. Turvey. "Long-Range Dependence in the Volatility of Commodity Futures Prices: Wavelet-Based Evidence." Physica A: Statistical Mechanics and Its Applications 389, 1(2010):79-90.

Shalini, V., and K. Prasanna. "Impact of the Financial Crisis on Indian Commodity Markets: Structural Breaks and Volatility Dynamics.” Energy Economics 53, 1(2016):40-57.

Teterin, P., R. Brooks, and W. Enders. "Smooth Volatility Shifts and Spillovers in U.S. Crude Oil and Corn Futures Markets." Journal of Empirical Finance 38, 1(2016):22-36.

Theriault, V., and D.L. Tschirley. "How Institutions Mediate the Impact of Cash Cropping on Food Crop Intensification: An Application to Cotton in Sub-Saharan Africa." World Development 64, 1(2014):298-310.

Timmer, C.P. "Farmers and Markets: The Political Economy of New Paradigms." American Journal of Agricultural Economics 79, 2(1997):621-27.

Torrence, C., and G.P. Compo. “A Practical Guide to Wavelet Analysis.” Bulletin of the American Meteorological Society 79, 1(1998):61-78.

Trujillo-Barrera, A., M. Mallory, and P. Garcia. "Volatility Spillovers in U.S. Crude Oil, Ethanol, and Corn Futures Markets." Journal of Agricultural and Resource Economics 37, 2(2012):247-62.

United Nations Conference on Trade and Development (UNCTAD) and Food and Agriculture Organization of the United Nations (FAO). Commodities and Development Report 2017: Commodity Markets, Economic Growth and Development. New York: United Nations, 2017.

Vivian, A., and M.E. Wohar. "Commodity Volatility Breaks." Journal of International Financial Markets, Institutions and Money 22, 2(2012):395-422.

Von Braun, J., and E. Kennedy. Commercialization of Subsistence Agriculture: Income and Nutritional Effects in Developing Countries. Washington, DC: International Food Policy Research Institute, 1986.

Weber, M.T., J.M. Staatz, E.W. Crawford, R.H. Bernsten, and J.S. Holtzman. "Informing Food Security Decisions in Africa: Empirical Analysis and Policy Dialogue.” American Journal of Agricultural Economics 70, 5(1988):1044-52.

\section{Appendix}

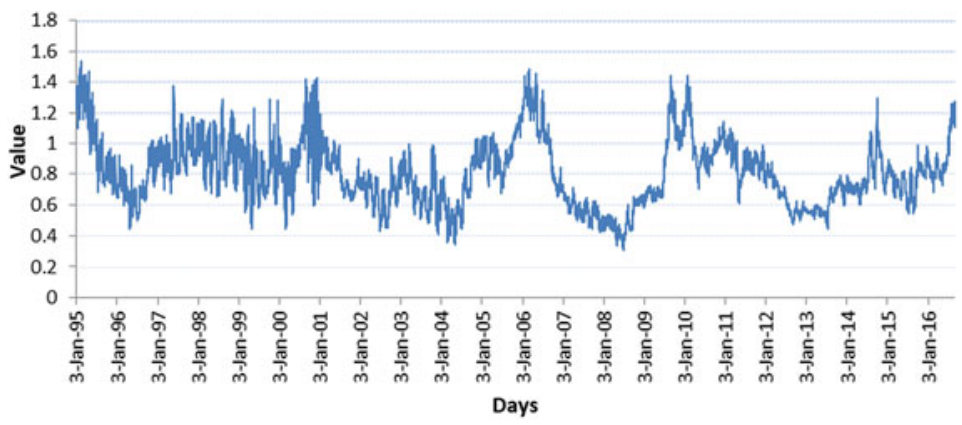

Figure A1. Cash crop price index versus staple food price index. 


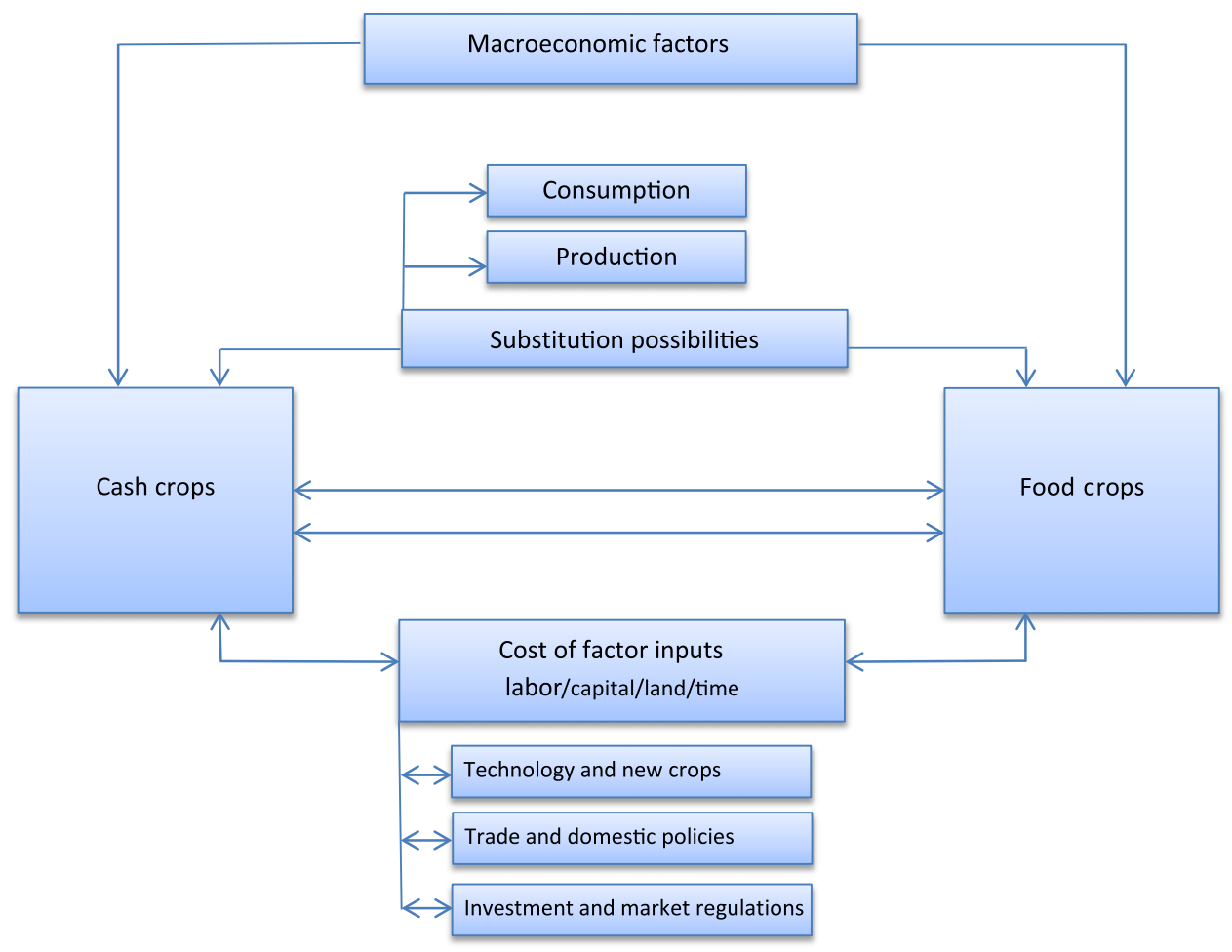

Figure A2. Interaction between cash crop and staple food prices: a conceptual framework. Notes: Aside from macroeconomic drivers, other underlying factors can cause cash crop and staple foods to correlate. These include factors related to the following: (1) changes in the cost of labor and other factors of production, (2) technological improvements and the introduction of a new farming activity that bids factor input costs, (3) trade and domestic policies, and (4) commodity investment and market regulations. Substitution possibilities in consumption and production between cash crops and staple foods in the physical market are rather limited and, hence, cannot explain the full extent of the price correlation.

Cite this article: Amrouk EM, Heckelei T, and Grosche S-C (2019). International Interdependence between Cash Crop and Staple Food Futures Price Indices: A Dynamic Assessment. Journal of Agricultural and Applied Economics 51, 450-471. https://doi.org/10.1017/aae.2019.12 